\title{
EVOLUCIÓN, RUPTURAS Y CONTRAMARCHAS EN EL CONSTRUCTIVISMO KANTIANO DE JOHN RAWLS
}

\author{
Fernando Aranda Fraga
}

Universidad Adventista del Plata, Argentina

\section{El Constructivismo Moral De John RAWLS ${ }^{1}$}

[...] las tres principales concepciones-modelo de la concepción de la justicia como equidad - la de sociedad bien-ordenada, la concepción de la persona, y la posición original -, son versiones especiales de nociones más generales. Lo que caracteriza a una doctrina kantiana es el modo particular como interpreta estas tres concepciones-modelos; especialmente característica es, por supuesto, su concepción de la persona como razonable y racional y como plenamente autónoma $\left[\ldots . .{ }^{2}\right.$

Así define Rawls qué es lo que fundamentalmente le interesa de Kant para incorporar a su constructivismo moral. ${ }^{3}$ Por supuesto que, comparado con lo que en tanto seguidor de Kant se declaraba en la $T J$, en

\footnotetext{
${ }^{1}$ Un muy bien documentado estudio sobre el constructivismo ético en Rawls ha sido publicado por Carlos I. Massini Correas, Constructivismo ético y justicia procedimental en John Rawls (México D.F.: Universidad Nacional Autónoma de México, 2004), pp. 7-62.

2 John Rawls, "Kantian Constructivism in Moral Theory", en John Rawls, Collected Papers. Editado por Samuel Freeman (Cambridge, Massachusetts: Harvard University Press, 1999), Capítulo 16, p. 306. Original publicado en Journal of Philosophy 77 (September 1980): 515-572. Hay versión castellana en: John Rawls, "El constructivismo kantiano en la teoría moral", en John Rawls, Justicia como equidad. Materiales para una teoría de la justicia. Traducción y edición de Miguel Angel Rodilla (Madrid: Tecnos, 1986), p. 140. De aquí en adelante toda vez que se cite este artículo, se lo hará directamente de la versión inglesa, publicada en 1999, en Collected Papers.

3 "Esta visión, aclara el profesor de Harvard, es grosso modo 'kantiana', aunque no es la visión del mismo Kant, sino sólo similar a ella". [Carlos I. Massini Correas, "Los dilemas del constructivismo ético. Análisis a partir de las ideas de John Rawls", Persona y Derecho 36 (1997): 183].
}

Philosophica, 31, Lisboa, 2008, pp. 103-125 
1971, dicha influencia ha quedado sustancialmente disminuida, como era de esperar ${ }^{4}$, dado los enormes problemas subyacentes en dicha obra para lograr congeniar el permanente dualismo kantiano del par noúmeno-fenómeno con los principales principios éticos rawlsianos, que terminaban quedando huérfanos allí donde con Kant su explicación requería la continuidad de la existencia del plano noumenal. En este tópico, veremos, entonces, qué es lo que lo une y qué lo separa de Kant, sin perder de vista el dato de que estamos en 1980, siete años pasaron ya desde la publicación de la obra magna de Rawls, Teoría de la justicia (A Theory of Justi$c e$, de aquí en adelante $T J$ ). Por tanto nuestro filósofo se halla en pleno periodo de transición entre lo que dio en llamarse una teoría de rango y alcance universal sobre la justicia y otra que, finalmente, ya en su horma final de Liberalismo politico (Political Liberalism, de aquí en adelante $P L$ ), se encontrará acotada a fuertes rasgos relativistas y deliberadamente antiuniversalistas, debido a la influencia que la crítica comunitarista ha ejercido sobre Rawls. Desenlace éste con el cual tampoco responde demasiado a sus principales adversarios, ni logra salir airoso de tales críticas, puesto que los cambios introducidos no le permitieron desviarse casi un ápice, siquiera, del corazón liberal, individualista y atomista que sesgó desde un principio y para siempre su concepción contractualista de la justicia como imparcialidad. ${ }^{5}$

De hecho, las variantes que introduce luego de 1971 en su teoría le han granjeado más abandono de seguidores que asimilación e incorporación de adversarios. Fueron muchos quienes defraudados por esta huida

4 "El impacto que su obra de 1971 produjo en el mundo académico anglosajón se debió, entre otras razones, a su postura crítica de la tradición utilitarista predominante. A diferencia de ésta, proponía una visión neokantiana de la sociedad liberal y presentaba las condiciones bajo las cuales es posible el perfeccionamiento de sus instituciones. Sin embargo, también implicaba una revisión de aspectos básicos de la filosofía de Kant. En ese sentido, es incorrecto interpretar a la Teoría de la justicia como una doctrina universalista tradicional, del tipo de un modelo adecuado para toda sociedad con independencia de su devenir histórico particular [...] Rawls fue alejándose así de un liberalismo de base kantiana como sostén teórico de la justicia como imparcialidad (fairness), al que en un principio parecía entender como el mejor representante de aquellas tendencias manifiestas en las sociedades democráticas occidentales, aunque rescataba en la ética de Kant el procedimiento de construcción de los principios de justicia y su aptitud para emanciparlos de una construcción de los principios de justicia y su aptitud para emanciparlos de una concepción metafísica o teológica previa”. [Jorge Raúl De Miguel, Visiones filosóficas de la democracia (Rosario: Asociación Argentina de Investigaciones Éticas, Regional Santa Fe, 2000), pp. 83-84].

${ }^{5}$ Un reciente estudio sobre las diferencias y semejanzas existentes entre el constructivismo de Kant y de Rawls, que abarca la totalidad de la obra publicada por este último, puede verse en el trabajo publicado por Onora O'Neill, "Constructivism in Kant and Rawls", en Samuel Freeman, ed., The Cambridge Companion to Rawls (New York: Cambridge University Press, 2003), pp. 347-367. 
del universalismo y del kantismo abandonaron la "escuela rawlsiana", si es que alguna vez se llegó a conformar un concepto semejante a partir de sus no escasos seguidores, ya que en definitiva, los actuales comentaristas de filosofía política y ética jurídica, a la hora de dar cierre y sentido abarcador a su juicio sobre la obra total de John Rawls, coinciden entre sí en que - a pesar de que se lo pueda catalogar teniendo en cuenta al menos la popularidad que alcanzó y las múltiples disciplinas que adhirieron a su doctrina - como el filósofo político más importante del siglo XX, no se conoce hoy día prácticamente alguien que se autodenomine como "rawlsiano", al menos avant la lettre.

\section{Más cerca de Dewey y Hegel: las rupturas (metafísicas) con el kantismo}

A partir de la publicación de su artículo en el que expone su noción constructivista de la moral ${ }^{6}$, Rawls comienza - al menos en forma declarada - a separarse de uno de sus principales mentores hasta el momento, especialmente en su obra mediante la cual se hizo mundialmente conocido: la $T J$. Al mismo tiempo proclama su adhesión a la versión formulada por John Dewey, mayormente conocido en EE.UU. como típico representante del naturalismo instrumental - y su cosmovisión pragmatista de la realidad. Con esto deja allanado el camino para que de aquí en más su concepción de la justicia como imparcialidad abandone el camino abierto dentro de la línea del universalismo, especialmente al modo kantiano, y llegue, finalmente, a contraer ciertos sesgos, propios del pragmatismo que comienza a influenciarlo, como así también de algunas certeras críticas que alzan su voz contra el universalismo y el carácter estrictamente hipotético y artificial de su teoría de la justicia. ${ }^{7}$ Para llevar a cabo este micro-

6 “[...] Estas ideas fueron eventualmente declaradas con nítidamente por filósofos iusnaturalistas tales como Hugo Grocio, Thomas Hobbes, Samuel Pufendorf y John Locke. Con la excepción parcial de Grocio, estos autores sostuvieron que no hay ningún significado moral o político inherente a la estructura de las cosas. Todo significado, o valor, es deseado o construido, e impuesto sobre un mundo natural que en sí mismo es amoral y apolítico". [Knud Haakonssen, Natural Law and Moral Philosophy. From Grotius to the Scottish Enlightenment (New York: Cambridge University Press, 1996), p. 102].

7 "Este rasgo que desdibuja el universalismo recogido en otros pasajes de la obra, es acentuado en 'Constructivismo kantiano'. Aquí Rawls pone especialmente el acento en la pretensión de explicitar y ordenar ciertos presupuestos arraigados en la cultura pública de las democracias occidentales. Sin embargo, el modo sistemático con que articula los conceptos centrales de la teoría, iluminan su función crítica respecto de aquéllas. Dentro de este marco profundiza el concepto de razón práctica a fin de disipar ciertas interpretaciones que se hicieron sobre la situación original presentada en Teoría de la justicia [...] Hay, también, una acentuación de los rasgos kantianos, sobre todo en lo que atañe a la prioridad de lo justo sobre lo bueno, que involucra un concepto de persona concebida como separada de sus fines, y una voluntad au- 
proyecto de explicitación de la ligera variante que ha sufrido su teoría, echa mano del recurso argumental acerca de las diversas opciones que, según Rawls, existen del constructivismo. Ahora, a partir de la nueva versión que ensaya de su constructivismo moral, será Dewey quien lo ayudará a evadirse del kantismo estricto que por entonces comienzan a criticarle las primeras voces comunitaristas. Dewey y su concepción demócrata protocomunitarista de la política y de la ética, le permitirán acercarse al hegelianismo, fuente de la mayoría de los comunitaristas, a la vez que lo inducirán, como es de suponer, a alejarse del maestro alemán, nacido en Königsberg, en el siglo XVIII:

[...] voy a examinar la noción de concepción moral constructivista, o, más exactamente, puesto que hay diferentes tipos de constructivismo, una variante kantiana de esa noción. La variante que voy a discutir es la de la justicia como equidad presentada en mi libro A Theory of Justice. Tengo dos razones para ello: una es que me depara la oportunidad de considerar ciertos aspectos de la concepción de la justicia como equidad que no he subrayado previamente y de exponer de forma más claras las raíces kantianas de dicha concepción. La otra razón es que la forma kantiana del constructivismo se conoce peor que otras concepciones morales tradicionales que nos son familiares, tales como el utilitarismo, el perfeccionismo y el intuicionismo. Creo que esta situación dificulta el progreso de la teoría moral. Por tanto, puede resultar útil simplemente explicar los rasgos distintivos del constructivismo kantiano, decir en qué consiste, tal como viene ejemplificado por la concepción de la justicia como equidad $[\ldots] .{ }^{8}$

Rawls afirma que "una de las intenciones de Hegel fue superar los muchos dualismos que, en su opinión, desfiguraban el idealismo transcendental de Kant, y Dewey compartió este énfasis a lo largo de toda su obra, a menudo acentuando la continuidad entre cosas que Kant separó nítidamente". Así, "Dewey se opone a Kant, a veces de forma bastante explícita y a menudo en los mismo lugares en los que la concepción de la justicia como equidad se separa de Kant", hecho que determina un fuerte aire de familia entre la "concepción de la justicia como equidad y la teoría moral de Dewey, afinidades que se explican por la intención común de superar los dualismos de la doctrina kantiana". ${ }^{9}$

\footnotetext{
tónoma. Este último rasgo está presente en la idea de constructivismo, que pone de manifiesto la inexistencia de un orden moral previo, apelando a la noción de justicia procedimental pura". [Graciela Vidiella, "La razón práctica en la teoría de Rawls", en Temas actuales de Filosofía (Salta: Universidad Nacional de Salta, 1991), pp. 620-621].

${ }^{8}$ John Rawls, "Kantian Constructivism in Moral Theory”, p. 303.

${ }^{9}$ Ibid.
} 
Las ventajas - a juicio del pensador de Harvard - de su asimilación del pragmatismo y constructivismo liberal deweyniano, son múltiples. ${ }^{10}$ Según Rawls, Dewey lo ayuda a distinguir más finamente su visión de la de Kant en lo que respecta a su concepción de la justicia como imparcialidad. Como resultado de esta asimilación Rawls se sitúa en una posición intermedia en relación a su anterior $T J$ y su última gran obra $P L$. Porque todo lo que ha hecho es poner en definitiva evidencia la falta de fundamento que presentaba su $T J$, entendida ésta, como él pretendía en 1971, a la manera kantiana, pues precisamente el dualismo insalvable de la realidad existente para Kant (noúmeno-fenómeno) constituía el mayor impedimento para que su $T J$ fuera, como antes lo declaraba el propio Rawls, kantiana en alto grado, con la excepción de sus pretensiones de universalidad y de autonomía; el resto de la influencia kantiana, al no aceptar su dualismo, quedaba colgado de la nada en Rawls. ${ }^{11}$ Ahora, a raíz de su acercamiento a Dewey, que no es en absoluto casual, hecho que se percibe especialmente en el trasfondo que opera detrás de $P L$, y que ya se revela en su anticipatorio artículo de 1985, publicado en Philosophy \& Public Affairs, resulta que los dualismos molestos del kantismo se vuelven perfectamente superables con el recurso de la influencia recibida de Dewey, y por ende, y a través suyo, de Hegel. Con ello ya se perfilan las intenciones rawlsianas de querer hacer más potable su teoría de la justicia como imparcialidad a sus críticos comunitaristas, hecho que se habrá de consumar, en cierto grado, con la publicación de $P L$.

He aquí, según creemos, la insistencia en este "alto en el camino" efectuado en 1980, intentando dar un giro hacia el modelo contiguo de la realidad y del yo, tal como es concebido por Hegel, y que a su vez les resultará más digerible y hasta un tanto gratificante a los comunitaristas; un giro que no es ontológico, sino más bien político, en el pleno sentido

10 “Ahora bien, frecuentemente señala Kant de alguna forma el requisito de la publicidad; [...] la concepción de la justicia como equidad, se separa, pues de Kant tanto en la primacía que asigna a lo social como en el ulterior aspecto de esa primacía contenido en la condición de publicidad plena. Creo que estas desviaciones permiten a la concepción de la justicia como equidad evitar algunos de los defectos que Dewey encontró en la visión kantiana". (Ibid., p. 340).

11 "Rawls habla también de otros elementos de su teoría como expresando exigencias kantianas; así la prioridad de la justicia sobre el bien, la teoría de bien, la condición de publicidad de los principios y el velo de ignorancia. También se han señalado como ideas y matices típicamente kantianos la prioridad de la libertad, la concepción del acto moral como acto racional de manera que lo injusto sería irracional, y el propósito de hallar una justificación para nuestro sentido común de justicia; rasgos formalistas, temperamento constructivo y sistemático, la prioridad del actor moral sobre las instituciones sociales y el rechazo del teleologismo (fines o principios externos a la voluntad que se autodetermina)". [Jesús Ignacio Martínez García, La teoría de la justicia de John Rawls (Madrid: Centro de Estudios Constitucionales, 1985), p. 141]. 
de la palabra. Es decir que no sabemos si se trata de algo real, pues se mueve en el ámbito de la apariencia. Pero habrá que esperar hasta la publicación del artículo de 1985 para poder leer en palabras de Rawls mismo este leve giro adoptado en su teoría, giro que, como afirmamos antes, no lo es tanto si dejamos de atenernos ni seguimos tan de cerca al hilo de su argumentación, siendo conscientes de que se trata siempre de lo mismo, de su ideología perenne, aunque presentada en un paquete de distinto peso y color. Entre tanto, continuemos seccionando analíticamente parte de las piezas del artículo de 1980.

Luego de haber afirmado su enlace con Dewey, Rawls continúa deslindando anteriores dependencias, declarando que si bien, al igual que Kant, pretende conectar la idea de persona moral con un procedimiento racional de construcción, su doctrina moral no ha de ser idéntica a la de Kant - como parecía serlo en su $T J$-, sino que de ella puede decirse que es "kantiana" sólo por analogía. Con esto, a su vez, y especificando diferenciaciones con su obra anterior, Rawls preanuncia las propiedades "políticas" de su argumentación sobre la justicia.

Lo distintivo de la forma kantiana del constructivismo es esencialmente esto: que especifica una determinada concepción de la persona como elemento de un procedimiento razonable de construcción cuyo resultado determina el contenido de los primeros principios de la justicia [...] La concepción de la justicia como equidad no es, evidentemente, la visión de Kant, estrictamente hablando; se separa de su tenor en muchos puntos. Pero el adjetivo 'kantiano' expresa analogía, no identidad; significa grosso modo que una doctrina se asemeja lo bastante a la de Kant en aspectos suficientemente fundamentales como para estar mucho más cerca de su visión que de la de otras concepciones morales tradicionales que es apropiado emplear como punto de comparación [...] En la visión kantiana que voy a presentar, las condiciones para justificar una concepción de la justicia sólo se dan cuando está establecida una base para el razonamiento político y el entendimiento dentro de una cultura pública. El papel social de una concepción de la justicia es permitir a todos los miembros de la sociedad hacerse mutuamente aceptables unos a otros sus comunes instituciones y arreglos básicos, y ello citando lo que públicamente se reconoce como razones suficientes, tal como esa concepción las identifica. ${ }^{12}$

Rawls señala en este trabajo que una de las razones análogas entre su concepción y la kantiana sobre la justicia es que, ante la falta de acuerdo entre personas morales sobre cómo deben estar articuladas la libertad y la igualdad de la que gozan, "una concepción kantiana intentará disipar tal

\footnotetext{
12 John Rawls, "Kantian Constructivism in Moral Theory”, pp. 304-305.
} 
conflicto", preguntando sobre el tipo de principios que "acordarían personas morales libres e iguales si estuvieran representadas imparcialmente”. Tal acuerdo, conjetura Rawls, suponiendo que se llegaría a alguno, "seleccionaría los principios de libertad e igualdad más apropiados y, por consiguiente, especificaría los principios de la justicia”. Hasta aquí, el constructivismo kantiano continúa brindándole apoyo para la construcción - artificial, ya que se hará bajo la forma de un contrato hipotético de la posición original y los principios de justicia que en esta instancia se determinan como los más justos - imparciales - para ambas partes. ${ }^{13}$

De este modo, afirma Rawls, la filosofía política tiene como meta descubrir las bases más profundas del acuerdo, aquellas que están ya asentadas en el sentido común de los ciudadanos y que se muestran capaces de resistir la reflexión crítica. Es así como puede ser socialmente construido el sentido de justicia, y la objetividad consiste, precisamente, en esta capacidad que la sociedad dispone de construir sus propios principios. Fuera de un procedimiento tal, no se ha de reparar - pues no existen, según Rawls - en la existencia de otros hechos morales.

[...] El constructivismo kantiano sostiene que la objetividad moral ha de entenderse en términos de un punto de vista social adecuadamente construido y que todos puedan aceptar. Fuera del procedimiento de construir los principios de justicia, no hay hechos morales. El que ciertos hechos hayan de contar, es algo que sólo se puede determinar desde dentro del procedimiento de construcción, esto es, a partir de los compromisos adoptados por agentes racionales de construcción cuando se encuentran debidamente representados como personas morales libres e iguales [...]. ${ }^{14}$

\section{Acerca del concepto rawlsiano de autonomía}

Luego de haber establecido Rawls en qué aspectos su constructivismo se relaciona con el de Kant, expone su idea dual de autonomía: la que él llama "autonomía racional", que es específica de Kant y que pervive en las partes que se encuentran en la posición original, dominio de la más pura imparcialidad, y la "autonomía plena", postulada por Rawls ${ }^{15}-$ se-

13 Ibid., p. 305.

14 Ibid., pp. 306-307.

15 "La autonomía racional de las partes en la sociedad contrasta con la autonomía plena de los ciudadanos en la sociedad. Así, la autonomía racional es una noción relativamente estrecha, y más o menos análoga a la noción kantiana de los imperativos hipotéticos (o a la noción de racionalidad de la economía neo-clásica); la autonomía plena es la de los ciudadanos en la vida diaria que piensan de sí mismos de un modo determinado y afirman y actúan a partir de los primeros principios de justicia que serían acordados. [...]”. (Ibid., p. 308). 
gún él - que es poseída sólo por los ciudadanos que conviven en la "sociedad bien ordenada", producto de la aplicación de los principios de justicia a las instituciones de la sociedad. Así es como Rawls pretende haber superado al kantismo y su constructivismo moral, mediante esta idea de "autonomía plena", la cual contrasta con la anterior, "racional", de Kant, que ha pasado a ser considerada como estrecha, por no permitir a los individuos llegar más allá de la posición original. ${ }^{16}$

Rawls está queriéndonos decir que su noción de "autonomía plena" rebasa la noción kantiana de autonomía, pues ésta equivale en Rawls a lo que él denomina como "autonomía racional". Ésta opera en una primera instancia, al comienzo, en la posición original, mientras los pactantes no disponen del conocimiento que les es negado por el velo de ignorancia, cuando deben elegir ciertos principios, de modo que éstos garanticen, a un mismo tiempo, el logro de sus propios intereses. Cuando estos principios llegan a ser aceptados por todos, los sujetos pactantes pasan inmediatamente a un estado de autonomía plena, puesto que acuerdan los principios que eligen de manera que lo racionalmente elegido - los principios imparciales de justicia - resulte algo razonable para la estabilidad de una "sociedad bien ordenada", tal como han de aplicarse los principios de justicia de ahí en más a fin de que se esta sociedad se autosostenga. ${ }^{17}$ En tanto la "autonomía plena" se refiere a una noción de autonomía de orden superior, que es alcanzada por los individuos sólo una vez liberados de los apetitos y deseos que los animó a buscar los principios imparciales de justicia capaz de permitirles una correcta y cooperativa convivencia social, la primera especie de autonomía, que Rawls llama "racional", permanecía ligada a los apetitos individuales y a la mera autoconservación, pero racional al fin, puesto que les permite garantizar la satisfacción de sus deseos y pasar así, una vez asegurado el orden social, a la "plenitud" de su autonomía moral. ${ }^{18}$

Expresado en un lenguaje de clave y matriz hobbesianas, llevando la comparación al terreno especulativo y sustituyendo la analogía Rawls-Kant, por la de Rawls-Hobbes, ambos conceptos rawlsianos de autonomía (autonomía racional y autonomía plena) serían más o menos similares, análogos, a los conceptos tan contrastables entre sí como los hobbesianos de estado natural-Estado social o político, porque su pasaje de uno a otro también está dado por la capacidad de los ciudadanos de establecer un pacto y formar gobierno mediante dicho acuerdo. La autonomía "racional" estaría aquí representada por la ley natural que induce a

\footnotetext{
${ }^{16}$ Cf. Ibid.

${ }^{17}$ Cf. Ibid., pp. 333-334.

18 Ibid., pp. 334-335.
} 
pactar y a respetar los pactos - acuerdos en lenguaje rawlsiano -, y la "plena" tendrá vigencia cuando los ciudadanos hobbesianos obedecen y respetan racionalmente las leyes, puesto que ello redundará en la estabilidad de la vida social y, por ende, en la protección de sí mismos y de sus propiedades. Aun así, parece que Rawls quiere a toda costa evitar constantemente que su concepto de cooperación social entre ciudadanos mutuamente desinteresados, y más bien el de "las partes mutuamente desinteresadas", se confunda con el de "naturaleza egoísta" que posee el hombre de Hobbes, propiedad fundamental que lo conduce racio-naturalmente a efectuar el pacto social. Notemos cómo lo expresa Rawls en una cita del artículo que estamos analizando:

[...] las partes simplemente están intentando garantizar y promover las condiciones necesarias para el ejercicio de las facultades que las caracterizan como personas morales. Ciertamente esta motivación no es ni heterónoma ni egocéntrica: esperamos e incluso deseamos que la gente se preocupe de sus libertades y oportunidades a fin de realizar esas facultades, y pensamos que muestran una falta de respeto de sí mismas y una debilidad de carácter si no lo hacen. Así, pues, el presupuesto de que las partes son mutuamente desinteresadas y, por tanto, preocupadas por asegurar sus propios intereses de orden supremo (o los de las personas a las que representan) no debería confundirse con el egoísmo. ${ }^{19}$

Resulta difícil en demasía leer pasajes como el transcripto al final del párrafo anterior y no pensar en la antropología hobbesiana que daba el sustento básico a la filosofía política del filósofo inglés del siglo XVII. En todo caso, quizás sólo nos quedaría por pensar, luego de esta cita que de paso ya nada tiene que ver con la moral kantiana - que, o bien Hobbes llegó más lejos que Rawls en cuanto a la profundidad de su análisis de la psiquis del hombre, dadas las consecuencias políticas y la teoría social que aquél quiso imponer, o bien que sabiendo Rawls esto de antemano, simplemente no quiso decirlo y menos aún reconocerlo, tal como se animó a hacerlo Hobbes, desnudando las graves falencias morales existentes en el corazón de su teoría contractual. Si éste fuera el caso, entonces tendríamos que decir que Hobbes, comparado con su heredero neocontractualista, dio vastas muestras de transparencia en cuanto a las consecuencias de su teoría política, o bien fue demasiado exhibicionista y exageró las consecuencias éticas de su doctrina. Teniendo en mente la crudeza con que Hobbes, sin dar casi vueltas y sin tapujos, presentó su teoría en el Leviathan, más bien tendemos a pensar que Hobbes fue, por lejos, más transparente que su heredero del siglo XX, quien, así, preten-

${ }^{19}$ Ibid., p. 315. 
dió hacer de su teoría de la justicia, y por ende de su moral, una presentación mucho más política que realista. ${ }^{20}$

\section{Principales divergencias respecto de Kant}

Por último, y para finalizar el comentario sobre el constructivismo kantiano en la teoría moral de Rawls - en cuanto a las diferencias que éste ha querido dejar aquí señaladas con respecto a Kant -, cabe señalar otra gran divergencia entre el alemán y el norteamericano nacido en Baltimore. Se trata de la orientación predominante que Kant le ha impuesto a su teoría moral y que, a juicio de Rawls, constituye una diferencia básica y que podrá ser juzgada, como una orientación pragmática en éste ${ }^{21}$, en tanto para Kant era, por sobre todas las cosas una orientación ética apelativa a la moral individual, y que como Rawls bien dice, se proyectaba luego, imperativo categórico mediante, al ámbito de lo social:

[...] aunque considero la concepción de la justicia como equidad como una concepción kantiana, difiere de la doctrina de Kant en importantes aspectos. Hago notar aquí que la concepción de la justicia como equidad asigna cierta primacía a lo social: esto es, el primer objeto de la justicia es la estructura básica de la sociedad, y los ciudadanos tienen que llegar en primer lugar a un entendimiento público sobre una concepción de la justicia aplicable a este objeto. Este entendimiento se interpreta a través del acuerdo unánime de las partes en la posición ori-

${ }^{20}$ Ibid., p. 334

${ }^{21}$ Al respecto del pragmatismo de Rawls y del giro que adquiere su filosofía política desde el artículo sobre el constructivismo kantiano en adelante, comenta K. O. Apel: “Un buen ejemplo de esta tendencia 'pragmática' de la filosofía moral actual lo constituye el desarrollo de la posición de John Rawls. [...] Pero la ulterior posición de Rawls en Political Liberalism ha cambiado en muchos respectos. Ha abandonado la pretensión de una fundamentación 'filosófica' independiente $-y$, en ese sentido, 'moral' - de la teoría de la justicia (obviamente, bajo el impacto de la tesis comunitarista de que todas las teorías 'filosóficas' de la moralidad deben ser dependientes de posiciones comprensivas de la metafísica). Rawls restringe ahora la pretensión de su teoría de la justicia a una proposición 'política' ('hipotética') que puede encontrar apoyo en la mayor parte de las 'doctrinas comprensivas' de lo 'bueno', y constituirse así en la base de un 'consenso solapado en el mundo político. [...] al abandonar la fundamentación filosófica de la justicia, Rawls abandona la posibilidad de un principio genuino de universalización de origen kantiano; es decir, de un principio que, en el nombre de su propia autoridad moral, puede ser dirigido contra aquellos tipos de 'consenso solapado' que de hecho pueden ser alcanzados frente a la actual constelación de posiciones comprensivas en el mundo político". [K. O. Apel, "Globalization and the Need for Universal Ethics" (inédito en el original en inglés), hay traducción castellana de José San Martín: "La globalización y la necesidad de una ética universal", Erasmus 1, 1 (1999): 12$-13]$. 
ginal. En contraste con ello, el tratamiento kantiano del Imperativo Categórico se aplica a las máximas personales de individuos sinceros y conscientes en la vida diaria [...] Pero esta comparación de mundos sociales se emprende individualmente por cada persona y al objeto de juzgar una determinada máxima personal. Así pues, Kant procede a partir del caso particular e incluso personal, de la vida diaria, y da por supuesto que este proceso, llevado a cabo correctamente, proporcionaría a la larga un sistema coherente y suficientemente completo de principios, incluyendo principios de justicia social. La concepción de la justicia como equidad se mueve en la dirección totalmente opuesta: su construcción parte de un acuerdo colectivo unánime regulador de la estructura básica de la sociedad, dentro de la cual todas las decisiones personales y asociativas han de hacerse en conformidad con este compromiso previo. ${ }^{22}$

Mucho más podría verse si siguiéramos analizando e interpretando las diferencias y similitudes entre las teorías constructivistas de Kant y de Rawls, acerca de la moral y de la justicia, pero creemos que en lo tratado hasta aquí hemos repasado los tópicos elementales.

En suma, podríamos sintetizar la posición constructivista de Rawls, expresando que su teoría de la justicia establece los siguientes lineamientos:

1. No existe un orden moral previo e independiente a la posición original en que se encuentran las partes. Fuera del procedimiento de construcción no hay hechos morales, sino que cualquier hecho es finalmente identificado según los principios resultantes. ${ }^{23}$

2. La objetividad en esta concepción constructivista es proporcionada mediante la conjunción entre los primeros principios establecidos de la concepción de la justicia y "nuestras convicciones consideradas en equilibrio reflexivo general y amplio". ${ }^{24}$

3. El acuerdo que logran las partes entre sí en la posición original no se trata de una elección radical, no está basado en razones, sino que es una especie de acuerdo fijado ad hoc, "mediante un puro fiat", dice Rawls, que como ciudadanos hemos de reconocer como válido. En la posición original las partes se manejan movidas por sus preferencias acerca de los bienes primarios que les interesan. ${ }^{25}$

4. El acuerdo es requerido debido a que "nuestra sociedad no está bien-ordenada: la concepción pública de la justicia y su forma de entender la libertad y la igualdad son objeto de disputas". Esto

\footnotetext{
22 John Rawls, "Kantian Constructivism in Moral Theory”, p. 339.

${ }^{23}$ Ibid., p. 354.

24 Ibid.

25 Ibid.
} 
implica que sea necesario, dada la circunstancia descripta aquí por Rawls, obtener "una base para la justificación pública". ${ }^{26}$

5. La propiedad fundamental poseída por los primeros principios en la concepción constructivista es que éstos son, más que verdaderos o falsos, razonables o irrazonables. Rawls afirma aquí que "se emplea 'razonable' en lugar de 'verdadero' no en virtud de alguna teoría alternativa de la verdad, sino simplemente para seguir una terminología que indica el punto de vista constructivista como opuesto al intuicionismo racional", lo cual, agrega Rawls, a pesar de esto, no impide que no pueda aplicarse la noción de verdad en el razonamiento moral. "Esos principios puede decirse que son verdaderos en el sentido de que serían acordados si a las partes en la posición original se les proporcionaran todas las creencias generales verdaderas que son relevantes". ${ }^{27}$

6. Además, según Rawls, su concepción de la justicia como imparcialidad no excluye la posibilidad de que exista sólo una concepción que sea la más razonable entre todas las demás. ${ }^{28}$

7. Rawls declara que su intención no ha sido demostrar el error del intuicionismo racional, sino simplemente establecer que la noción de objetividad de esta posición "es innecesaria para la objetividad". Su meta no era, desde un comienzo, "defender al constructivismo", sino describirlo por contraste contra el intuicionismo racional. El constructivista, en vez de afirmar que ha alcanzado un orden dado y fijo de la moral, dirá que su concepción de la justicia lograda ha de ser "la más razonable para nosotros". ${ }^{29}$ Esto denota con claridad meridiana la posición relativista que va adquiriendo la teoría rawlsiana de la justicia y que ha de evidenciarse con mucho mayor grado en los capitulos de PL.

8. Tal criterio de objetividad no se alcanza, según la expresión de Sidgwick, por "el punto de vista del universo", sino referenciándola con "el punto de vista social adecuadamente construido, un ejemplo del cual es el marco proporcionado por el procedimiento de la posición original". Este es un punto de vista "públicamente compartido por los ciudadanos de una sociedad bien-ordenada, y los principios que provienen de él son aceptados por ellos como dotados de autoridad con respecto a las pretensiones de los individuos y asociaciones". 30

${ }^{26}$ Ibid., pp. 354-355.

${ }^{27}$ Ibid., p. 355.

${ }^{28}$ Ibid.

${ }^{29}$ Ibid., p. 356.

${ }^{30}$ Ibid. 
9. Este procedimiento constructivista permite enunciar principios capaces de promover intereses del más alto orden para todos, definiendo los términos imparciales de cooperación social entre los ciudadanos, quienes, de tal modo, al invocar estos principios que comparten junto a los restantes miembros de su comunidad política, lo hacen tanto por propio interés como por los intereses de sus congéneres sociales. ${ }^{31} Y$ continúa Rawls con una afirmación que adopta cierto tinte y raigambre hobbesiano: "Así, pues, el acuerdo esencial en los juicios de justicia no surge del reconocimiento de un orden moral previo e independiente, sino de la afirmación por parte de todos de la misma perspectiva social dotada de autoridad". 32

10. Finalmente la concepción constructivista de Rawls "nos capacita para explotar la flexibilidad y fuerza de la elección racional sujeta a restricciones apropiadas". De tal modo, continúa Rawls, "la posición original no es una base axiomática", de la cual se deriven determinados principios, "sino un procedimiento para determinar principios más acordes con la concepción de la persona" que resulte más verosímil de sostener implícitamente en una moderna sociedad democrática. Todo ello será suficiente para lograr un entendimiento entre la libertad y la igualdad, capaz de lograr un acuerdo público viable que pueda satisfacer el peso respectivo de ambas pretensiones. ${ }^{33}$

Este acento puesto, o al menos declarado por su autor, en la moral de su teoría constructivista, será modificado con el correr de los años, hecho que ha de quedar definitivamente evidenciado a partir de la publicación de su siguiente gran obra, $P L$.

\section{EL CONSTRUCTIVISMO KANTIANO SEGÚN POLITICAL LIBERALISM (1993)}

\section{Metamorfosis del constructivismo moral kantiano en constructivismo político}

Al comienzo de la Conferencia III de $P L$, Rawls declara que en ésta analizará "el constructivismo político en contraste con el constructivismo

31 Ibid.

32 Ibid.

33 Ibid., pp. 357-358.

34 Ver la obra de Victoria Davion \& Clark Wolf, The Idea of a Political Liberalism. Essays on Rawls (Lanham, Maryland: Rowman \& Littlefield Publishers, 2000), 
moral de Kant", como así también "con el intuicionismo racional como una forma del realismo moral". Esto será efectuado bajo el firme propósito de que el constructivismo político ${ }^{35}$ sea capaz de proveer al liberalismo político "de una apropiada concepción de objetividad". ${ }^{36}$

En esencia, ambas versiones de su teoría constructivista no han cambiado, salvo en el énfasis político que ahora, trece años después, quiere imprimirle Rawls a su concepción de la justicia, tal como en una etapa intermedia, en 1985, lo había anticipado con claridad meridiana, al publicar su artículo "Justice and Fairness: Political not Metaphysical". El propio Rawls señala en la introducción a $P L$ que la razón de haber reescrito este artículo sobre la fundamentación constructivista de su teoría, y de publicarlo ahora en forma revisada en su nueva obra, se debe a que después de haber publicado aquella primera versión en 1980 y a partir de las observaciones recibidas por varios de sus colegas, con quienes fue progresivamente discutiendo asuntos allí tratados, logró aclarar "los puntos oscuros" de su obra $T J$, a fin de poder ahora corregirlos y mejorarlos.

$\mathrm{Al}$ concluir esta tercera conferencia, Rawls resume las diferencias más relevantes que ahora incluye esta nueva versión de su ensayo del ' 80 : Circunscribió el alcance del constructivismo político a valores políticos, "que caracterizan el campo de lo político", en lugar de pretender dar una "explicación general de los valores morales". ${ }^{37}$ Estos valores políticos, en una democracia constitucional, son considerados como distintivos, ya que se elaboran mediante "la idea fundamental de la sociedad como un sistema justo de cooperación entre ciudadanos libres e iguales, en tanto que ciudadanos razonables y racionales". ${ }^{38}$

Según el constructivismo político, cuando una concepción de la justicia se fundamenta en concepciones y principios de la razón práctica que

Introducción, § 3: “The Argument of Political Liberalism”, pp. 4-8. Los editores, aludiendo al propósito de la idea central de esta obra, Rawls defiende la idea de que la concepción de la justicia como imparcialidad se focaliza en asuntos referidos a su estabilidad y legitimación, asuntos que no habían sido centrales en su anterior obra, la $T J$.

35 Acerca del constructivismo político véase: Nythamar de Oliveira, Rawls (Río de Janeiro: Jorge Zahar Editor, 2003), pp. 27-33.

36 John Rawls, Political Liberalism, Paperback edition (New York: Columbia University Press, 1996), III, p. 89. Versión original, en inglés, publicada en 1993 por la misma editorial. Esta versión incluye, además: "Introduction to the Paperback Edition", pp. xxxvii-lxii; y "Lecture IX. Reply to Habermas", pp. 372-434. Hay traducción castellana de Sergio René Madero Báez en: John Rawls, Liberalismo político. Primera edición en español (México: F.C.E., 1995). Utilizaremos siempre la versión original en inglés.

37 Ibid., III, § 8, p. 126.

38 Ibid. 
han sido expuestos con corrección, la concepción de la justicia ha de ser, entonces, "razonable para un régimen constitucional". 39

Este consenso, tal como luego Rawls mismo lo explicará en mayor detalle en la conferencia $\mathrm{V}$, "no representa un mero modus vivendi" ${ }^{40}$, sino que es moral, tanto en sus objetivos como en su contenido". ${ }^{41}$ "Cuando hablamos de la verdad moral de una concepción política, la valoramos desde el punto de vista de nuestra doctrina comprensiva". ${ }^{42}$ Las explicaciones religiosas, filosóficas o metafísicas de la veracidad de los juicios morales, como así tampoco su validez, son incumbencia del constructivismo político, por tanto tampoco son criticadas por Rawls. Su norma de corrección es la razonabilidad y no necesita ir más allá de esto - según nuestro autor -, debido a que sus objetivos quedan restringidos al campo de lo político. ${ }^{43}$ Así, recurriendo estrictamente a razones políticas, los ciudadanos apelan no sólo a lo que consideran "públicamente razonable", sino a aquello "que todos ven como las razones morales correctas desde su propio punto de vista comprensivo". 44

La concepción política de la justicia se restringe a que los ciudadanos, siendo razonables y racionales, sean capaces de alcanzar un acuerdo libre e informado "sobre cuestiones constitucionales esenciales y sobre las materias básicas de la justicia". De tal modo que la concepción política se conforma con poder llegar a ser una base razonable de la razón pública, y con esto le basta. ${ }^{45}$ Apegarnos a una concepción de "lo razonable" tiene la ventaja de que en tanto no hay - ni puede haberla - más que una doctrina comprensiva verdadera, tal como se ha visto, sí "pueden existir muchas doctrinas razonables". ${ }^{46}$ Esta noción sobre lo razonable es más apropiada, como justificación pública, "que la idea de la verdad moral". Según Rawls, "sostener una concepción política como verdadera, y sólo por esa razón considerarla el fundamento apropiado de la razón pública, es exclusivo, e incluso sectario". ${ }^{47}$

\footnotetext{
39 Ibid.

${ }^{40}$ Cf. Bernard Dauenhauer, "A Good Word for a Modus Vivendi", y Scott Hershovitz, "A Mere Modus Vivendi?", en Victoria Davion \& Clark Wolf, The Idea of a Political Liberalism. Essays on Rawls (Lanham, Maryland: Rowman \& Littlefield Publishers, 2000), Capítulos 11 y 12, pp. 204-220, 221-230.

${ }^{41}$ Rawls, Political Liberalism, III, § 8, p. 126.

42 Ibid., III, § 8, p. 127.

43 Ibid., III, § 8, pp. 127-129.

${ }^{44}$ Ibid., III, § 8, p. 128.

45 Ibid.

46 Ibid.

${ }^{47}$ Ibid., III, § 8, p. 129.
} 


\section{La antesala del Liberalismo político: ¿filosofía política exenta de me-} tafísica? ${ }^{48}$

Ingresamos aquí en otro de los temas claves de Rawls, en lo que se refiere a los orígenes y transición hacia su obra $P L$. El asunto de la carencia de metafísica pretendida por Rawls constituye un aspecto importante en el desarrollo de su obra, la cual incluye ciertas analogías con Kant, especialmente si lo comparamos con la relación que el sabio alemán estableció en su Crítica de la razón pura entre conocimiento científico y conocimiento metafísico, aunque en este caso, el filósofo de Nueva Inglaterra lo aplicará al ámbito práctico. Nos introducimos, de este modo, en un tema de alta relevancia en la filosofía política de Rawls y que ha de marcar el sentido que adoptará en sus artículos de aquí en adelante, como así también el sentido de su obra del '93. La analogía, aquí, con Kant, es que así como éste, en el ámbito estrictamente gnoseológico y epistemológico, se "quitó de encima" a la metafísica, negándole su carácter de ciencia, semejantemente hará ahora Rawls al intentar despojar a la política y su teoría de la justicia - de toda posible "contaminación" con la metafísica. ${ }^{49}$ Esto le ha de otorgar el rédito que está buscando para lograr "universalizar", aunque parezca teóricamente contradictorio, al máximo posible, su teoría de la justicia como imparcialidad. Esta búsqueda de universalidad más amplia que Rawls busca se explica mejor como la pretensión de que todas las formas contemporáneas de liberalismo y posiciones afines al mismo puedan asimilar su teoría, sin por ello tener que hacer concesiones respecto de sus creencias fundamentales, tal como ha sucedido, de hecho, con ciertas formas contemporáneas, filo-liberales del comunitarismo norteamericano.

\section{La tradición en la cual se inserta el proyecto de Rawls}

El proyecto filosófico rawlsiano es heredero de la Ilustración y como tal se inserta en la tradición racionalista del pensamiento. Pero, aún así, reconoce algunos importantes límites que han sido puestos sobre el tapete con el advenimiento de la posmodernidad. En una época en que ya no hay fundamentos últimos sobre los cuales asirse, se ha resquebrajado todo un mundo de seguridades. La reconstrucción de la razón práctica deberá ser llevada a cabo en condiciones diferentes a las de Kant. Está claro, por

48 Aníbal Fornari, "Ética y ontología. La formación de la conciencia crítica en el equilibrio reflexivo", Tópicos. Revista de Filosofia de Santa Fe V, 5 (2000): 47-52.

${ }^{49}$ Cf. John Rawls, "Justice as Fairness: Political not Metaphysical", en Collected Papers, Capítulo 18, pp. 388-414. 
ejemplo, el abierto rechazo que hace Rawls de la metafísica kantiana, quedándose solamente con su teoría moral empírica. ¿Qué le queda, entonces, a esta razón? Acorde con el giro pragmático-lingüístico que ha tomado el pensamiento, apenas quedan ciertos mecanismos lógico-formales que han de servir para justificar la existencia de un pequeño núcleo de máximas y de normas. Para Rawls, queda a salvo el intento de separar la facticidad de la validez y de apelar a la imparcialidad, hacia lo cual acometerá a partir de su concepción sustantiva de la justicia. Surge, entonces, la pregunta crítica central: ¿hasta dónde y desde dónde será posible esta apelación a la imparcialidad?, y otra aún más profunda: ¿qué queda de la ética una vez recortado - si es resuelto - de su ámbito el problema de la justicia?

\section{Un paralelismo limitado entre Kant y Rawls}

Rawls se declara, en muchos de sus escritos, bajo la influencia de la moral kantiana. Sobre todo cabría afirmar esto del primer Rawls, si es posible establecer una división entre dos periodos un tanto diferenciados en nuestro autor. ${ }^{50}$

En lenguaje rawlsiano, diversas nociones propias de la ética kantiana, son analizadas y hechas suyas, a partir de sus propios puntos de vista e intereses. Por ejemplo, para comenzar, luego de su afirmación antes citada, que la fuerza de la ética de Kant radica en algo diferente de su generalidad y universalidad ${ }^{51}$, Rawls enfatiza el hecho de que el filósofo alemán comienza "con la idea de que los principios morales son objeto de elección racional". ${ }^{52}$ Tales principios operan como una ley moral mediante la cual los hombres son capaces de autogobernarse, racionalmente, en un Estado ético. Así es como una filosofía moral se convierte en el estudio de una concepción que no es más que el resultado de una decisión racional convenientemente definida. ${ }^{53}$ Como consecuencia de semejante idea - continúa Rawls - se obtiene que desde el momento en que conside-

50 “Quizás la más famosa recreación de la teoría contractual kantiana sea la presentada por la teoría de la justicia de John Rawls. Esta resurrección rawlsiana de la tradición contractual kantiana no sólo ha estimulado una serie de lo que ha sido dado a conocer como los pensadores 'contractualistas', incluyendo a pensadores como Brian Barry and T. M. Scanlon, sino además ha producido una nueva tradición de anticontractualistas conocidos como los comunitaristas, a quienes analizaremos en la segunda parte de este capítulo". [David Boucher \& Paul Kelly, The Social Contract from Hobbes to Rawls (Routledge: London, 1994), p. 8].

${ }^{51}$ Rawls, A Theory of Justice, Edición revisada (Cambridge, Massachusetts: The Belknap Press of Harvard University Press, 1999), § 40, p. 251.

52 Ibid.

53 Ibid. 
ramos los principios morales como un "reino de fines", dichos principios "deben no sólo ser aceptados por todos, sino también públicamente conocidos". "Finalmente, Kant supone que tal legislación moral ha sido acordada bajo condiciones en las cuales los hombres han sido caracterizados como seres libres y racionales". ${ }^{54} \mathrm{Y}$ aquí viene la aplicación propiamente rawlsiana de estas nociones kantianas asimiladas, porque el filósofo de Harvard se aventura a declarar que su "descripción de la posición original es un intento de interpretar tal concepción", si bien matiza su declaración, afirmando que él no desea "probar su interpretación sobre la base de los textos de Kant". ${ }^{55}$ Aún cuando pueda haber quienes deseen leer a Kant de manera diferente, su propia idea e intención es que las observaciones que habrá de realizar a continuación de su exposición, bien podrían entenderse como sugerencias que permitan "relacionar la justicia como imparcialidad con el punto cúlmine de la tradición contractualista en Kant y en Rousseau". ${ }^{56}$

A renglón seguido, Rawls traza un orden paralelo entre la argumentación kantiana sobre la concepción autónoma de la ética, y su propia noción del "velo de ignorancia" [the veil of ignorance]. Según Rawls, para Kant, una persona debe, a fin de actuar moralmente, elegir sus principios de acción, como "la expresión más adecuada posible, de su propia naturaleza, como un ser libre y racional". Tales principios no se adoptan debido a la posición social que ellos ocupan, ni tampoco según el tipo de sociedad en que viven, ni por los dotes que naturalmente poseen, ni según las cosas específicas que desean. "Actuar según tales principios sería hacerlo en forma heterónoma". La analogía mencionada está dada, según Rawls, en que "el velo de ignorancia priva a las personas situadas en la posición original [the original position], del conocimiento que los capacitaría para elegir principios en forma heterónoma". Así es como las partes implicadas en el contrato social rawlsiano realizan en forma conjunta sus elecciones, "como personas libres, iguales y racionales, sabiendo solamente que las tales circunstancias dan lugar al surgimiento de la necesidad de los principios de justicia". ${ }^{57}$

Rawls asegura que las condiciones mencionadas en su propia teoría contractual aparecen con claridad en los escritos éticos kantianos, tomados en conjunto, lo cual hace de su teoría algo muy cercano a la de Kant. Especialmente coloca la fuerza de su argumentación en el hecho de que "los principios de su accionar no dependen de contingencias naturales o sociales, como así tampoco reflejan sus respectivos planes de vida ni las

\footnotetext{
${ }^{54}$ Ibid., § 40, p. 252.

55 Ibid.

56 Ibid.

57 Ibid.
} 
aspiraciones que los motivan". ${ }^{58}$ Es por ello que Rawls llega a afirmar que "los principios de justicia son, además, imperativos categóricos en el sentido kantiano". Y entonces pasa a definir lo que el alemán entiende por "imperativo categórico": "un principio de conducta que se aplica a una persona en virtud de su naturaleza como ser libre, igual y racional. La validez del principio no presupone que uno tenga un deseo o fin particular". ${ }^{59}$ Contrariamente, ante un imperativo hipotético se "asume que éste nos conduce a dar ciertos pasos como un medio efectivo para lograr un fin específico". ${ }^{60}$ Si se deseara alguna cosa particular, ya sea que se trate de algún tipo de sentimiento o de placer, el imperativo que a esto corresponde sería de carácter hipotético. Por el contrario, continúa Rawls, "el argumento para los dos principios de justicia no supone que las partes tengan fines particulares, sino sólo que ellos desean ciertos bienes primarios" ${ }^{61}$ Rawls asegura que estos bienes que él llama "primarios" son cosas razonables de querer, cualquiera sea el fin que cada particular desee para sí, puesto que desear estos denominados "bienes primarios" [primary goods] es algo propio de la naturaleza humana, racional misma, lo cual existe siempre y no interfiere con los fines particulares que cada cual pueda tener y de hecho tiene. ${ }^{62}$

La preferencia por los bienes primarios es derivada, entonces, sólo a partir de la hipótesis más general acerca de la racionalidad y las condiciones de la vida humana. Actuar conforme a los principios de justicia es hacerlo a partir de imperativos categóricos en el sentido de que éstos se aplican a nosotros cualesquiera sean nuestros fines particulares. Esto refleja simplemente el hecho de que ninguna contingencia aparece como premisa de sus derivaciones. ${ }^{63}$

También dice Rawls que su presuposición acerca del "desinterés mutuo concuerda con la noción kantiana de autonomía proporcionando otro fundamento más para esta condición", por lo cual, concluye, "ahora podemos agregar que de esta presuposición sobre el desinterés mutuo se sigue la libertad que rige en la elección de un sistema de fines particulares", pues el marco de libertad existente en el momento de la "adopción de una concepción sobre el bien está solamente limitado por principios que se deducen a partir de una doctrina que no impone restricciones pre-

\footnotetext{
58 Ibid.

59 Ibid., § 40, p. 253.

60 Ibid.

61 Ibid.

62 Ibid.

63 Ibid.
} 
vias sobre tales concepciones". ${ }^{64}$ Para esto sirve la presuposición sobre el desinterés mutuo que hay en la posición original; es lo que da soporte a esta idea. Restringir sus fines en algún sentido u orientación específica, sería restringir de manera arbitraria la libertad reinante en dicha situación. Además, continúa argumentando Rawls, "si se concibiera a las partes como altruistas, o persiguiendo ciertos tipos de placeres, entonces los principios elegidos se aplicarían [...] sólo a personas cuya libertad quedaría restringida a elecciones compatibles con el altruismo o el hedonismo". ${ }^{65}$ Tal concepción sobre el bien y las restricciones que le son impuestas a priori, a decir de Rawls, "son el resultado de una interpretación de la situación contractual que no coloca limitaciones previas sobre lo que los hombres puedan desear". De este modo, "hay una multitud de razones para motivar la premisa - propuesta por Rawls - del desinterés mutuo", y concluye su argumentación - mediante la cual busca demostrar su conexión con el principio kantiano de autonomía -, afirmando que "esta premisa no es simplemente una cuestión de realismo sobre las circunstancias de justicia o un modo de hacer asequible la teoría, sino que esto además se conecta con la noción kantiana de autonomía" (la negrita es nuestra). ${ }^{66}$

\section{Conclusión: el uso que Rawls hace del lenguaje kantiano y su adop- ción de un "Kant à la carte"}

Luego de una digresión que Rawls hace en su exposición, acerca de una supuesta dificultad en la teoría kantiana puesta en evidencia por Sidgwick ${ }^{67}$, el filósofo harvardiano intenta despejarla echando mano de nociones típicas, sumamente fuertes, pertenecientes a la filosofía general y a la cosmovisión kantianas. Nos referimos aquí a conceptos propios del lenguaje con que Kant acostumbra a expresar sus más caras nociones metafísicas, y que, por tanto, sólo encajan dentro de su sistema interpretativo, que al inicio de su deambular filosófico ha formulado acerca del rango de la ciencia. Nos referimos a su división del mundo existente en dos realidades absolutamente diferentes e incompatibles entre sí, y la decantación disciplinaria que ha hecho dentro del espectro de lo que hasta el momento era denominado y conocido como "conocimiento científico", negándole este carácter al conocimiento metafísico. ${ }^{68}$ Vale la pena detenernos en las propias palabras de Rawls acerca de este aspecto:

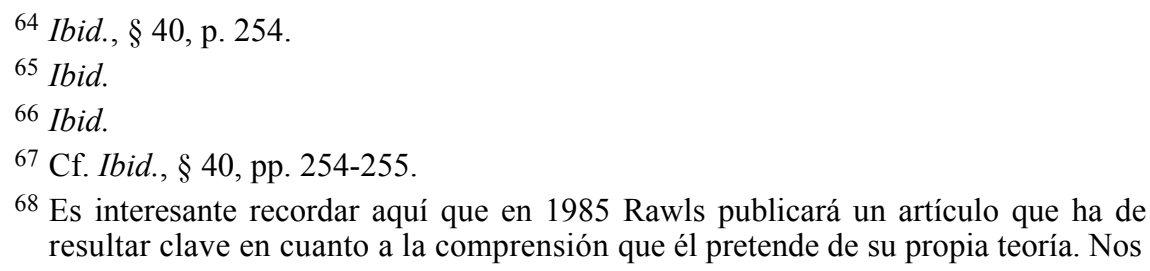


Mi sugerencia es que pensemos la posición original como el punto de vista desde el cual los seres noumenales contemplan el mundo. Las partes, como seres noumenales, tienen libertad total de elegir los principios que deseen; pero tienen también el deseo de expresar su naturaleza como miembros racionales e iguales del reino inteligible, precisamente con esta libertad de elección, esto es, como seres capaces de observar el mundo de este modo y de expresar tal perspectiva en sus vidas como miembros de la sociedad [...] La descripción de la posición original interpreta el punto de vista de los seres noumenales, lo cual significa que son seres libres e igualmente racionales. Nuestra naturaleza como tales seres se muestra cuando actuamos a partir de principios que elegiríamos cuando esta naturaleza es reflejada en las condiciones que determinan la elección. De tal manera los hombres exhiben su libertad e independencia de las contingencias naturales y sociales, actuando de un modo en que ellos podrían reconocer en la posición original. ${ }^{69}$

Rawls señala que quienes interpretan la ética kantiana como una doctrina moral de leyes, no han logrado entenderlo, pues queda claro, según Rawls, que el propósito de Kant "es profundizar y justificar la idea rousseauniana de que la libertad consiste en actuar conforme a una ley que nos damos a sí mismos, lo cual no nos conduce hacia una moral de leyes austeras, sino a una ética de respeto mutuo y autoestima". ${ }^{70} \mathrm{Y}$ en nota al pie, Rawls afirma que para confirmar su interpretación puede verse lo que Kant afirma sobre educación moral en The Critique of Practical Reason, parte II. ${ }^{71}$

A todo esto, agrega Rawls en este mismo parágrafo 40, que su constructo de la posición original "puede verse, entonces, como una interpretación procedimental de la concepción kantiana de autonomía y del imperativo categórico". ${ }^{72}$ En esta posición se eligen los principios reguladores del reino de los fines, así como la descripción de la situación explica el sentido por el cual expresamos nuestra naturaleza como seres libres, iguales y racionales que somos, al actuar según tales principios. Tales nociones - continúa Rawls - ya "no son más puramente trascendentales y ca-

referimos a "Justice as Fairness: Political not Metaphysical", trabajo escrito bajo la intención de que sus intérpretes traten de evitar ver en su teoría cualquier atisbo de conocimiento de carácter metafísico, y restringirla, así, a mera teoría sobre práctica política, con lo cual, en otras palabras, Rawls le enviaba un mensaje a cualquier intérprete de su pensamiento que pusiera en evidencia presuposiciones subyacentes e inevitables de carácter metafísico, ontológico y hasta antropológico.

${ }^{69}$ Rawls, A Theory of Justice, § 40, pp. 255-256.

70 Ibid., § 40, p. 256.

${ }^{71}$ Ibid., Nota al pie N. ${ }^{\circ} 32$, p. 256.

72 Ibid. 
rentes de conexiones explicativas de la conducta humana. [...] Es cierto que me he desviado de la concepción de Kant en varios puntos [...] pero dos aspectos deben ser notados": ${ }^{73}$ 1) "He asumido que la elección de la persona como un ser noumenal es una elección colectiva", y la relevancia de esto radica en que los principios elegidos han de ser aceptados por el resto, desde el momento en que todos son seres libres y racionales, "cada uno debe tener igual oportunidad para adoptar los principios públicos de la comunidad ética", lo cual "significa que, como seres noumenales, todos consienten con estos principios". ${ }^{74}$ 2) "He dado por sentado que todo lo que saben las partes es que ellos están sujetos a las condiciones de la vida humana. Al estar en las circunstancias de la justicia, se encuentran situados en el mundo junto a otros hombres, quienes como ellos, enfrentan limitaciones tales como la escasez moderada y las demandas de la competencia". ${ }^{75}$ Estas restricciones naturales constituyen la base desde la cual son elegidos los principios que han de regular la libertad. ${ }^{76}$ En cambio, la libertad de otras inteligencias, tales como Dios, por ejemplo, no entra en esta concepción, dado que su tipo de libertad no está sujeta a semejantes condiciones. ${ }^{77}$ Rawls agrega que parecería que Kant cree que su doctrina se aplica a todos los seres racionales, incluyendo entre éstos a Dios y a los ángeles. ${ }^{78}$ De ser así, la situación social que ocupan los hombres en el mundo aparentemente no jugaría rol alguno en cuanto a la determinación de su teoría sobre los primeros principios de justicia. ${ }^{79}$ Rawls concluye el parágrafo en el que se ha dedicado a mostrar la raigambre kantiana de su teoría y sus principales puntos de contacto, con la afirmación de que él mismo realmente no cree en esta última breve descripción de la ética kantiana, en relación con la naturaleza de los seres noumenales, "pero - continúa - no puedo discutir aquí este asunto. Es suficiente

73 Ibid., § 40, pp. 256-257.

${ }^{74}$ Ibid. Rawls afirma a continuación que más adelante ha de definir el sentido por el cual este acuerdo unánime se constituye en la mejor expresión de la naturaleza de cada ser singular, a lo cual se dedica en el $\S 85$. Por el momento afirma que tal naturaleza colectiva de la elección no deja a un lado los intereses particulares de las personas, cuestión que ahora decide no abordar.

75 Ibid., § 40, p. 257.

76 Ibid.

77 Ibid.

${ }^{78}$ Con esto último se denota que hay en Rawls una confusión inmensa en lo que respecta a la metafísica de Kant y el lugar que ocupan en su cosmovisión los seres que no están expuestos, o mejor dicho mediados, por una intelección dependiente de las coordenadas espacio-temporales y las restantes doce categorías, mecanismos gnoseológicos, solamente aplicables al mundo fenoménico, que él desarrolla en la Crítica de la razón pura.

79 Rawls, A Theory of Justice, § 40, p. 257. 
decir que si yo estoy confundido, la interpretación kantiana de la justicia como imparcialidad es menos fiel a las intenciones de Kant que aquello que yo estoy actualmente inclinado a suponer (o imaginar)". 80

Así fue como la noción de "autonomía de la voluntad", su libertad e independencia de nociones del bien, dio pie para que moralistas posteriores a Kant introdujeran la noción de "autonomía absoluta". A partir de esta autonomía el hombre se da a sí mismo sus normas. Este es el caso de John Rawls y de muchos otros filo kantianos. Rawls, fundándose en su personal interpretación del kantismo, afirma explícitamente no partir de ninguna concepción del bien. ${ }^{81}$ Esto le permitirá la "ventaja" de coincidir con una pluralidad de concepciones acerca de lo que es bueno y con un sinnúmero de proyectos de vida.

\title{
RESUMEN
}

A partir de la publicación de un artículo en el que expone su noción constructivista de la moral (1980), Rawls comienza - al menos en forma declarada a separarse de Kant, uno de sus principales mentores hasta entonces, especialmente respecto de aquella primera adhesión original efectuada en $A$ Theory of Justice. Al mismo tiempo proclama sus simpatías conceptuales con la filosofía política de John Dewey. Para llevar a cabo este microproyecto de explicitación de los cambios que ha sufrido su teoría, echa mano del recurso argumental acerca de las diversas variantes que, según Rawls, existen del constructivismo. A partir de la nueva versión que ensaya de su constructivismo moral, iniciará su abandono del kantismo estricto que en los años setenta comenzaron a criticarle las primeras voces comunitaristas.

Palabras clave: John Rawls - Kant - ética jurídica - justicia - constructivismo moral

\begin{abstract}
Starting in a paper where he defines his constructivist notion of morality (1980), Rawls begins - at least explicitly - to grow apart from Kant, one of his major mentors up to the moment, especially regarding that first original support given in A Theory of Justice. At the same time, he reveals himself as sympathizing with the political philosophy of John Dewey. In order to accomplish this microproject where he makes explicit the changes affecting his theory, he resorts to a reasoning based on the supposedly variants that, according to Rawls, are present in constructivism. Out of this new version of moral constructivism, he begins drifting apart from the rigorous Kantianism the first community voices had began to criticize in him in the 70's.
\end{abstract}

Keywords: John Rawls - Kant - law ethics - justice - moral constructivism

${ }^{80}$ Ibid.
${ }^{81}$ Ibid., $\S 40$, pp. 252-254. 